\title{
Sustained normothermia in septic shock and the energy transfer required: a report of a pilot feasibility study using newer-generation surface cooling devices
}

James R Anstey, Peter R Forrest, Helen Cass, Paul Emery, Christian Karcher, Megan Kelly, Lidgalem Mesfin, David Moore and Rinaldo Bellomo

There is significant uncertainty about the potential role of temperature control in the intensive care unit (ICU) in general, but more specifically in septic shock patients. ${ }^{1,2}$ Common techniques for temperature control have been limited by minimal effect (eg, paracetamol, fans or air blankets), undesirable side effects (eg, non-steroidal antiinflammatories), or being burdensome (eg, heavy sedation, paralysis with surface cooling; intravascular cooling devices $^{3}$ ). In contrast, the potential of newer-generation surface-cooling devices to achieve temperature control more simply has created the possibility of studying temperature modulation in the septic ICU population.

In our adult tertiary ICU, we aimed to assess feasibility and effectiveness of an external, water-based temperature control device (Arctic Sun 5000, BARD) to achieve and maintain strict normothermia in febrile, intubated, septic shock patients by comparing this with temperature control using conventional methods in our unit. Moreover, using minute-by-minute data about the water flow and water temperature to and from the device, we aimed to estimate the energy exchange required for normothermia in sepsis given the lack of data in this regard.

We applied the device to nine febrile (defined as a single temperature reading $>38.0^{\circ} \mathrm{C}$ ), septic shock ICU patients who had been intubated for less than 24 hours, and aimed to maintain temperature at $37.0^{\circ} \mathrm{C}$ for a maximum of 5 days or until extubation. Temperature in the case patients was measured via an oesophageal temperature probe. Septic shock was defined by vasopressor requirement, accompanied by a serum lactate $>2.0 \mathrm{mmol} / \mathrm{L}$, in patients receiving antibiotics for suspected or proven infection. We excluded patients with urosepsis, poor skin integrity, traumatic brain injury, cardiac arrest, those not expected to survive their ICU stay, and those for whom the treating intensivist objected to this temperature target. The ICU nurse inspected skin integrity every 6 hours. This study was performed with Melbourne Health ethics approval (QA2016159).
To compare the ability of this temperature control device with conventional therapy, we performed a retrospective 1:1 matching using the ICU database. First, we identified patients with a primary diagnosis of "sepsis with shock other than urinary tract" admitted to the ICU within the previous 2 years. Then, we used a hierarchy of age (within 10 years), Acute Physiology and Chronic Health Evaluation (APACHE) III score (within 10 points) and sex to match cases to controls. We calculated individual patient mean (standard deviation [SD]) temperature for the duration of their intubation and up to 5 days, and then compared groupwise mean (SD) temperatures. Temperature values were taken as recorded, without adjusting for the site of measurement, from the time that temperature control therapies were initiated. We also estimated the burden of time spent with temperature above $38.0^{\circ} \mathrm{C}$ in each group by calculating the percentage of all measurements above this target.

Characteristics, source of sepsis, location of temperature measurement, treatments of fever, and outcomes are summarised in Table 1. Historical controls were comparable in most respects, except for being younger (Table 1). While all case patients had their temperature measured using an oesophageal probe, controls had their temperature measured in a variety of locations, reflecting a previously unstandardised approach to temperature measurement in the ICU. The consistency of measurement site within any single patient allowed serial assessment of that individual patient's response to attempted fever control.

In a case patient with central nervous system infection, the target temperature was changed to $36.0^{\circ} \mathrm{C}$ due to intracranial hypertension complicating subdural empyema.

A comparison of temperatures between cases and controls is shown in Figure 1.

The mean temperature in the case group was $37.1^{\circ} \mathrm{C}$ (SD, 0.57); whereas in the control group the mean was $37.7^{\circ} \mathrm{C}$ (SD, 0.65$)$; difference $0.60^{\circ} \mathrm{C}(95 \% \mathrm{Cl},-0.01$ to $1.21 ; P=0.05)$. The total burden of measured temperatures exceeding $38.0^{\circ} \mathrm{C}$ was $1425 / 25243(5.6 \%)$ in the case 


\begin{tabular}{|c|c|c|c|}
\hline & Cases & Controls & $P^{*}$ \\
\hline Age (years), median (IQR) & $43.5(39.5-62.0)$ & $34.0(30.0-59.5)$ & 0.06 \\
\hline BMI $\left(\mathrm{kg} / \mathrm{m}^{2}\right)$, median (IQR) & $37.0(28.3-45.8)$ & $34.1(31.9-36.7)$ & 1 \\
\hline APACHE III score, mean (SD) & $81 \pm 32$ & $83 \pm 28$ & 0.66 \\
\hline \multicolumn{4}{|l|}{ Site of infection } \\
\hline Chest & 4 & 4 & \\
\hline Endocarditis & 1 & 2 & \\
\hline Bowel & 2 & 2 & \\
\hline Prosthetic joint & 1 & & \\
\hline Brain & 1 & & \\
\hline Unclear & & 1 & \\
\hline \multicolumn{4}{|l|}{ Temperature control devices } \\
\hline $\begin{array}{l}\text { Water-based external cooling } \\
\text { device }\end{array}$ & 9 & & \\
\hline Cooling blanket & & 5 & \\
\hline Fan & & 1 & \\
\hline Paracetamol & & 4 & \\
\hline \multicolumn{4}{|l|}{$\begin{array}{l}\text { Location of temperature } \\
\text { measurement }\end{array}$} \\
\hline Oesophagus & 9 & & \\
\hline Nasal & & 5 & \\
\hline Bladder & & 3 & \\
\hline Pulmonary artery & & 1 & \\
\hline $\begin{array}{l}\text { Days of invasive ventilation, } \\
\text { median (IQR) }\end{array}$ & $6.3(2.8-12.5)$ & $10.0(6.3-14.8)$ & na \\
\hline Renal replacement therapy in ICU & $3 / 9$ & $2 / 9$ & na \\
\hline $\begin{array}{l}\text { Length of ICU stay (days), } \\
\text { median (IQR) }\end{array}$ & $8(7-15)$ & $13(8-18)$ & na \\
\hline Died in ICU & $0 / 9$ & $3 / 9$ & na \\
\hline Died in hospital & $1 / 9$ & $3 / 9$ & na \\
\hline
\end{tabular}

the median energy required to cool febrile patients to normothermia over the first hour was $379 \mathrm{~J} / \mathrm{s}$ (Watts) (interquartile range [IQR], $338-434 \mathrm{~J} / \mathrm{s}$ ) while a median of $43 \mathrm{~J} / \mathrm{s}$ (IQR, 19.5-80.5 J/s) of cooling was required over the first 12 hours. The initial energy required is comparable to that needed to operate a typical household refrigerator, suggesting why simpler therapies (eg, air cooling blanket) might have limited success in treating fever. ${ }^{4}$ Moreover, the fact that three of the case patients received continuous renal replacement therapy during this period - another source of heat loss - means that we are likely to have slightly underestimated the true heat loss required to achieve the target temperature. After day 1 , normothermia could generally be maintained with a median of $19.5 \mathrm{~J} / \mathrm{s}$ (IQR, -1.4 to $59 \mathrm{~J} / \mathrm{s})$ of warming, indicating that most patients were being gently warmed with the energy equivalent to what is needed for a light bulb.

With regards to tolerability of this system, three out of nine patients received boluses of sedation to control shivering, while two out of nine patients had minor skin reactions (temporary skin marking only) as assessed by the treating nurse. No patients died in the ICU, while one patient died in hospital.

\section{Conclusions}

Rapid, predictable, and tight patients versus $84 / 194(43 \%)$ measurements in controls $(P<0.001)$.

Wealso estimated the heat transfer required to maintain the patient's target temperature (heat transfer $=\Delta$ temp $\times$ mass of water $\times$ specific heat of water $=4.184 \mathrm{~J} / \mathrm{g}^{\circ} \mathrm{C}$ ), using minuteby-minute water temperature to and from the device, minute-by-minute water flow rates, and assuming that any energy transfer independent of the device was negligible (Figure 2). During the initial period of temperature control, temperature control in septic shock patients, even in patients with obesity, can be achieved with this surface cooling device. Moreover, the burden of time spent with fever above $38.0^{\circ} \mathrm{C}$ appears considerably lower with this device over conventional techniques for temperature control. Finally, this study gives new insight into the considerable energy required, especially initially, to cool febrile septic patients. The low ICU mortality observed provides support for further studies of this approach to temperature control in septic shock. 
Figure 1. Comparison of mean temperatures in cases compared with historical controls

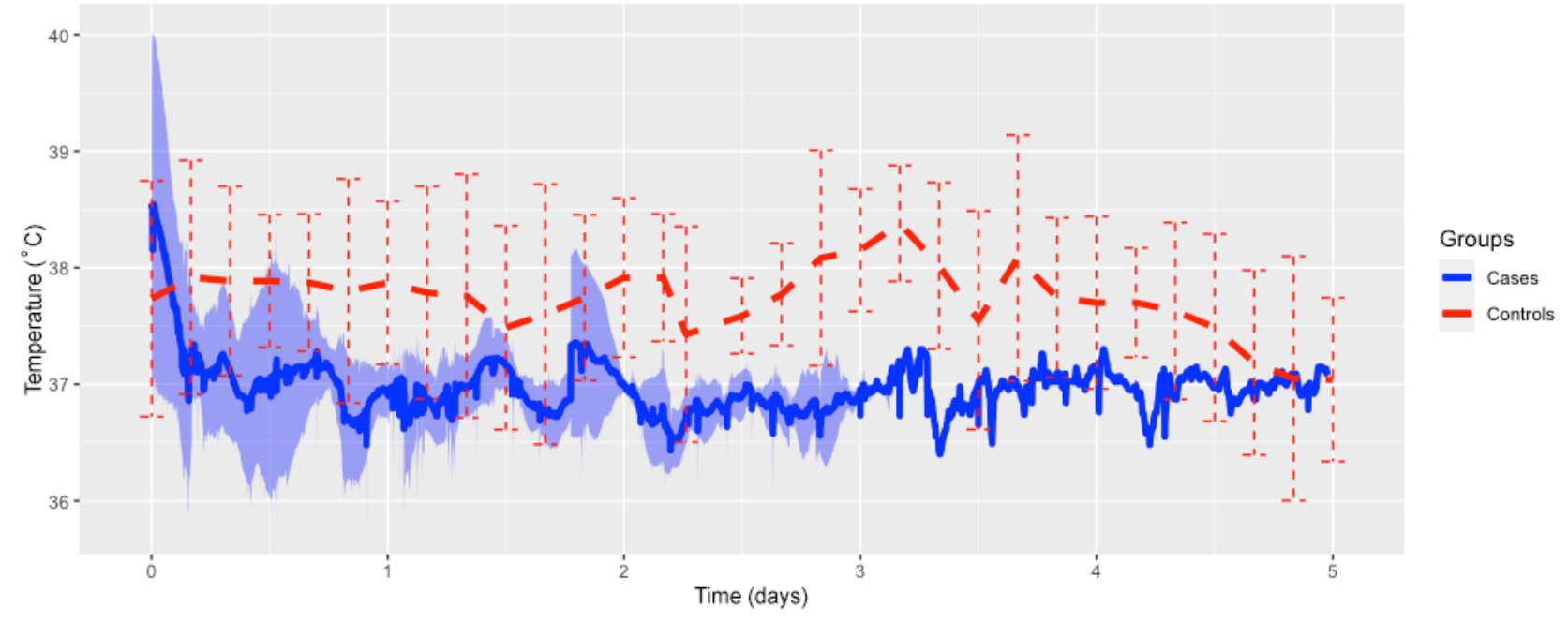

Cases are represented by the continuous line and ribbon (standard deviation) and controls by the dotted line and dotted bar (standard deviation). "Time (days)" refers to the time after initiation of temperature control therapy.

Figure 2. Median energy transfer to achieve and maintain normothermia $\left(37.0^{\circ} \mathrm{C}\right)$ in septic shock patients

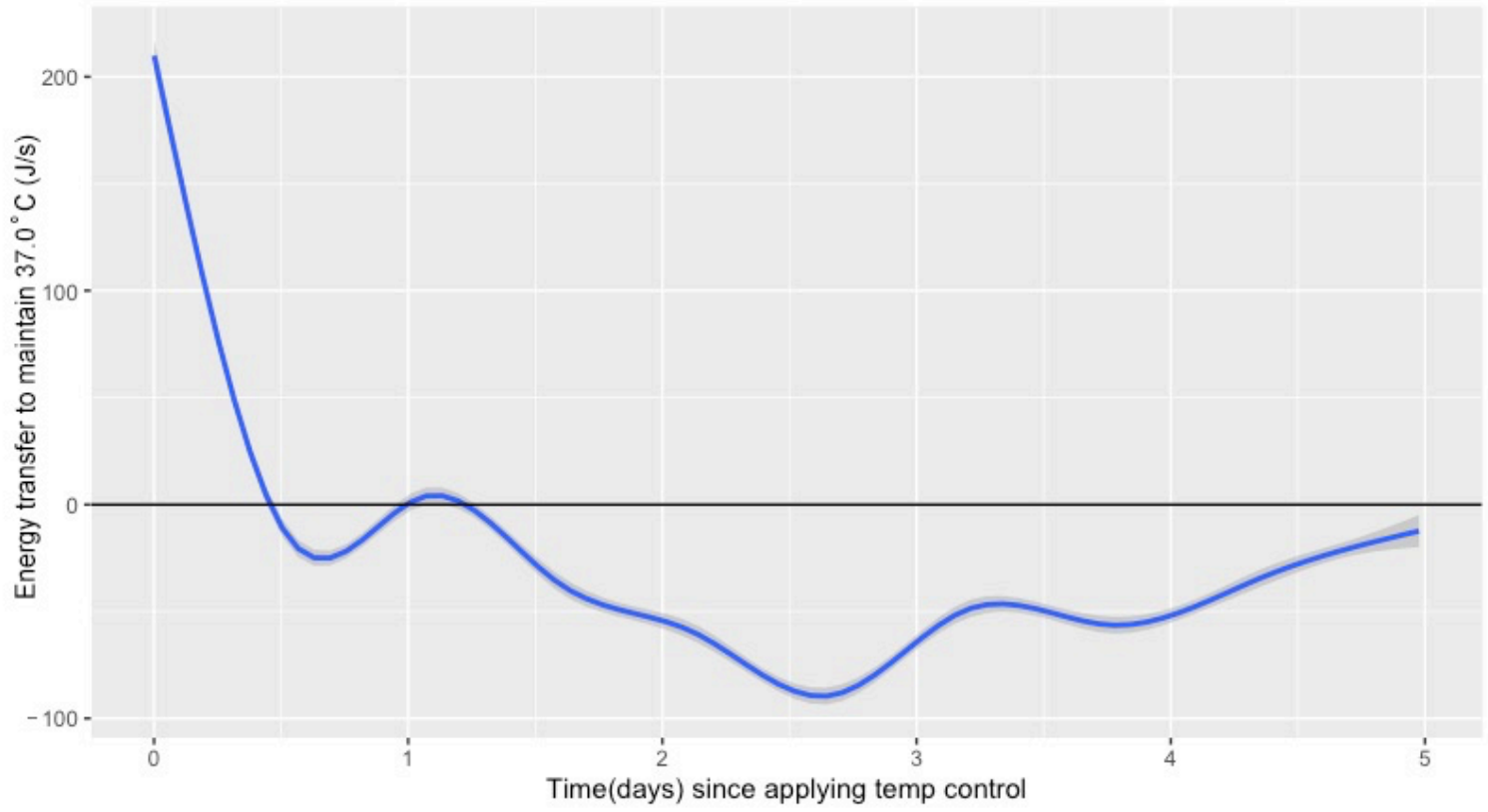

Temp = temperature. A positive value indicates cooling, whereas a negative value indicates warming the patient. 


\section{RESEARCH LETTERS}

Acknowledgements: This study was performed with support from the Royal Melbourne Hospital Research Foundation and BARD.

\section{Competing interests}

None declared.

\section{Author details}

\author{
James R Anstey ${ }^{1}$ \\ Peter R Forrest ${ }^{1}$ \\ Helen Cass $^{1}$ \\ Paul Emery ${ }^{1}$ \\ Christian Karcher ${ }^{1}$ \\ Megan Kelly \\ Lidgalem Mesfin ${ }^{1}$ \\ David Moore ${ }^{1}$ \\ Rinaldo Bellomo ${ }^{1,2}$
}

1 Department of Intensive Care, Royal Melbourne Hospital, Melbourne, VIC, Australia.

2 Centre for Integrated Critical Care, School of Medicine, University of Melbourne, Melbourne, VIC, Australia.

Correspondence: james.anstey@mh.org.au

\section{References}

1 Schortgen F, Clabault K, Katsahian S, et al. Fever control using external cooling in septic shock: a randomized controlled trial. Am J Respir Crit Care Med 2012; 185: 1088-95

2 Dallimore J, Ebmeier S, Thayabaran D, et al. Effect of active temperature management on mortality in intensive care unit patients. Crit Care Resusc 2018; 20: 150-63.

3 Polderman $\mathrm{KH}$. How to stay cool in the intensive care unit? Endovascular versus surface cooling. Circulation 2015; 132: 152-7.

4 Mayer S, Commichau C, Scarmeas N, et al. Clinical trial of an air-circulating cooling blanket for fever control in critically ill neurologic patients. Neurology 2001; 56: 292-8. 